\title{
TRATAMENTO FUNGICIDA EM SEMENTE DE MILHO SUPER-DOCE ${ }^{1}$
}

\author{
NILZA PATRÍCIA RAMOS², JULIO MARCOS FILHO ${ }^{3}$, JULIANA ALTAFIN GALLI ${ }^{4}$
}

\begin{abstract}
RESUMO - Neste trabalho, procurou-se avaliar a influência do tratamento fungicida no potencial fisiológico e na sanidade de sementes de milho híbrido super-doce DO-04, separadas por diferenças quanto ao formato. Foi utilizado delineamento inteiramente casualizado, em esquema fatorial 2 x $3 \times$ 4, compreendendo dois formatos de semente (retidas em peneira $15 \mathrm{x} \mathrm{3/4",} \mathrm{representando} \mathrm{as} \mathrm{sementes}$ arredondadas, e em peneira 20, representando as achatadas), três lotes e quatro tratamentos fungicidas (testemunha, Fludioxonil, Captan TS + Thiabendazol e Captan TS + Thiram PS). Avaliaram-se a germinação, o vigor (velocidade de germinação, teste de frio e envelhecimento acelerado) e a sanidade de semente. Foi verificado que as sementes arredondadas de milho híbrido super-doce DO-04 apresentam germinação e vigor mais elevados, em comparação às achatadas; os tratamentos fungicidas favorecem o vigor, sendo as combinações Captan + Thiabendazol e Captan + Thiram eficientes para o controle de F. moniliforme, Cephalosporium sp. e Penicillium sp..
\end{abstract}

Termos para indexação: Zea mays L., germinação, vigor, patógenos.

\section{FUNGICIDE TREATMENT OF SUPER SWEET CORN SEEDS}

\begin{abstract}
The objective of this research was to evaluate the effect of fungicide treatment on the physiological potential and seed health of DO-04 super sweet corn hybrid seeds classified by differences in shape. For this, pure seeds of the DO-04 hybrid harvested in 2004 were used. A completely random design was used in a $2 \times 3 \times 4$ factorial scheme, i.e. two seed shape classes (flat and round), three seed lots and four fungicide treatments (untreated seeds, Fludioxonil, Captan TS + Thiabendazol, and Captan TS + Thiram PS). After the fungicide treatments, germination, vigor ( germination speed, cold test, accelerated aging) and seed health tests were performed. Results showed that germination and vigor of round DO-04 hybrid super sweet corn seeds were higher than the flat ones. In addition, combinations of Captan + Thiabendazol and Captan + Thiram were efficient to control F. moniliforme, Cephalosporium sp. and Penicillium sp and were beneficial to seed vigor.
\end{abstract}

Index terms: Zea mays L., germination, vigor, pathogens.

\section{INTRODUÇÃO}

Sementes de milho (Zea mays L.) pertencentes ao grupo Super-doce (gene recessivo shrunken $-s h 2$ ) possuem, de modo geral, menor porcentagem de germinação quando

${ }^{1}$ Submetido em 04/01/2007. Aceito para publicação em 30/01/2007. Parte do Programa de Doutoramento da primeira autora.

${ }^{2}$ Pesquisadora A, Dra. Embrapa Meio Ambiente, CEP: 13820-000, Jaguariúna, SP.npramos@cnpma.embrapa.br comparadas ao milho comum (Waters-Jr e Blanchette, 1983). Esse desempenho inferior é atribuído, principalmente, à menor quantidade de amido, à cristalização de açúcares no interior das células do endosperma e à presença de espaços vazios entre a camada de aleurona e o pericarpo, que tornam
${ }^{3}$ Prof. Titular do Depto de Produção Vegetal, USP/ESALQ, C.P.9 - CEP. 13418-900, Piracicaba, SP. Bolsista CNPq. jmarcos@esalq.usp.br

${ }^{4}$ Pesquisadora Científica I, Apta Regional Centro Norte, CEP: 15830-000, Pindorama, SP. julianagalli@aptaregional.sp.gov.br 
o pericarpo frágil e sensível a danos físicos e à invasão por patógenos (Douglas et al., 1993; Nascimento et al., 1994).

A presença de patógenos pode alterar significativamente o desempenho de plântulas em campo e o comportamento da semente durante o período de armazenamento, sendo os efeitos mais pronunciados quando se tratam de organismos colonizadores de tecidos internos da semente (Machado, 2000). No caso de semente de milho, a presença de Fusarium moniliforme (Sheld.), Diplodia maydis (Berk.) Sacc., F. graminearum Schwabe e Cephalosporium sp. é muito freqüente e pode causar doenças de parte aérea de plantas (Luz, 1997), enquanto Aspergillus spp. e Penicillium spp. destacam-se no armazenamento (Machado, 2000).

Os danos decorrentes da ação de patógenos em semente de milho, considerados economicamente significativos, têm sido reduzidos pelas empresas produtoras de semente com o uso de tratamento com fungicida (Pereira, 1986; Fessel et al., 2003). O tratamento realizado diretamente sobre a superfície da semente pode ser uma opção rápida, eficiente e não onerosa para o controle de patógenos, desde que os produtos aplicados causem impacto reduzido ao ambiente e sejam efetivos para a proteção contra os microrganismos de solos e para a preservação da qualidade da semente durante o armazenamento.

Em cultivares que predispõem as estruturas da semente à ação severa de patógenos, Machado (2000) afirma que o tratamento fungicida deve ser considerado mais enfaticamente, refletindo de modo negativo no estabelecimento do estande. Nesse sentido, o milho super-doce, por apresentar desempenho germinativo deficiente ocasionado pela elevada reserva de açúcares no endosperma ou ao possível menor vigor natural da semente determinado pelo genótipo (McDonald et al. 1994), pode se beneficiar da ação de fungicidas.

Além dos cuidados com a sanidade, Waters-Jr e Blanchatte (1983) afirmam que a redução da porcentagem de emergência das plântulas de milho super-doce se deve, entre outros fatores, ao manuseio incorreto dos lotes, prejudicando a qualidade da semente. Assim, os procedimentos de secagem e beneficiamento merecem atenção especial no processo de controle de qualidade. Assim, a etapa de classificação da semente pela espessura e/ou largura, características determinantes da forma, que separa os lotes por peneiras, pode contribuir sensivelmente para melhor qualidade (Carvalho e Nakagawa, 2000).

$\mathrm{O}$ efeito da forma e do tamanho da semente sobre o vigor ainda é assunto controverso, dentro da literatura disponível. Wolf et al. (1952), citados por Shieh e McDonald (1982), afirmam que a forma da semente de milho é devida, em grande parte, à pressão exercida pelo pericarpo sobre a semente adjacente, durante a fase de enchimento de grão, e que essa pressão é menor nas sementes desenvolvidas no ápice e na base da espiga, tornando-as arredondadas após a maturação. Sabe-se, também, que os óvulos da base da espiga são os primeiros a ser fertilizados, resultando em sementes maiores que as do ápice, o que indica o acúmulo de quantidades superiores de reservas. Isso pode favorecer o desempenho da semente de milho super-doce, graças à redução de espaços vazios entre o pericarpo e a camada de aleurona (Styer e Cantliffe, 1983). Entretanto, em função do formato, as sementes do ápice e da base da espiga são mais danificadas mecanicamente, o que pode facilitar a ação de patógenos (Peterson et al., 1995).

Para evitar a ação negativa de patógenos sobre a semente, as empresas produtoras vêm utilizando o tratamento com fungicidas. O formato e o tamanho da semente, além das doses do produto, se incluem entre os fatores que podem interferir na eficácia desse procedimento (Machado, 2000). Em face dessas considerações, avaliou-se influência do tratamento fungicida no potencial fisiológico e na sanidade de sementes de milho híbrido super-doce DO-04 separadas por diferenças quanto ao formato.

\section{MATERIAL E MÉTODOS}

O trabalho foi realizado no Laboratório de Análise de Sementes e no Laboratório de Patologia de Sementes dos Departamentos de Produção Vegetal e de Entomologia, Fitopatologia e Zoologia Agrícola, respectivamente, da Escola Superior de Agricultura "Luiz de Queiroz"/USP, em Piracicaba, SP.

Foram utilizados três lotes de semente do milho híbrido super-doce DO-04 (Dow AgroSciences ${ }^{\circledR}$ ) produzidos na safra 2003/04. De cada lote, foram retiradas duas amostras, uma de sementes arredondadas, retidas na peneira de crivos oblongos de $15 \mathrm{x} 3 / 4$ " [semente com densidade de $1,77 \mathrm{~g} \mathrm{~mL}^{-1}$, determinada pelo método de Kniep e Mason (1989) e peso de 100 sementes de 17,00 g, seguindo determinação de Brasil (1992)] e outra de sementes achatadas, retidas em peneira de crivos circulares de 20/64". (sementes com densidade de 1,46 g. mL $\mathrm{m}^{-1}$ e peso de 100 sementes de $14,00 \mathrm{~g}$ ); obtendo-se um total de seis tratamentos. Posteriormente, cada tratamento foi separado em quatro sub-amostras submetidas à aplicação de três produtos fungicidas, mantendo-se também uma testemunha não tratada.

Assim, o delineamento experimental utilizado foi o inteiramente casualizado, distribuído em esquema fatorial 
$3 \times 2 \times 4$, sendo três lotes de sementes (L1, L2 e L3), dois formatos (semente arredondada e achatada) e quatro tratamentos fungicidas [testemunha não tratada, tratamento com Fludioxonil SC (150 mL p.c. ou 3,75 g i.a./100 kg de sementes), Captan TS (150 g p.c. ou 122,50 g i.a. . $100 \mathrm{~kg}^{-1}$ de semente) + Thiabendazol PM (80 g p.c. ou 48,00 g i.a. . $100 \mathrm{~kg}^{-1}$ de semente) e Captan TS (150 g p.c. ou 122,50 g i.a. $.100 \mathrm{~kg}^{-1}$ de semente $)+$ Thiram SC (350 mL p.c. ou 168,00 g i.a. . $100 \mathrm{~kg}^{-1}$ de semente), em quatro repetições.

Para o tratamento fungicida, as sementes de cada subamostra foram colocadas em sacos plásticos, misturadas aos produtos e homogeneizadas por fricção. Após o tratamento, foram secadas à sombra e embaladas em sacos de papel, até o início dos testes descritos a seguir:

a) germinação - realizada em quatro repetições de 50 sementes para cada tratamento, utilizando rolos de papel umedecidos 2,5 vezes o seu peso seco, mantidos a $25^{\circ} \mathrm{C}$, em câmaras próprias para germinação. A contagem final foi realizada aos sete dias após a semeadura, segundo as Regras para Análise de Sementes (Brasil, 1992), computando-se a porcentagem de plântulas sem quaisquer alterações,

b) velocidade de germinação - avaliada durante o teste de germinação, computando-se diariamente como germinadas as sementes com protrusão da raiz primária, sendo expressa pelo coeficiente de velocidade (IVG), calculado de acordo com Maguire (1962),

c) teste de frio - conduzido de acordo com Caseiro e Marcos Filho (2002), com quatro repetições de 50 sementes para cada tratamento, acondicionadas em bandejas plásticas $(34,0 \times 23,0 \times 7,0 \mathrm{~cm})$, contendo $2,0 \mathrm{~kg}$ de substrato $(3: 1-$ três partes de areia para uma parte de terra), umedecido até $60 \%$ de sua capacidade de retenção, com água previamente resfriada a $10^{\circ} \mathrm{C}$. Para reduzir a evaporação, as bandejas foram mantidas no interior de sacos plásticos e, posteriormente, transferidas para câmara fria, a $10^{\circ} \mathrm{C}$, por sete dias. Vencido esse período, transferiu-se o material para germinador a $25^{\circ} \mathrm{C}$, com avaliação aos cinco dias, considerando vigorosas as sementes que possibilitaram o desenvolvimento de plântulas sem quaisquer alterações,

d) envelhecimento acelerado - realizado pelo método das mini-câmaras (Marcos Filho, 1999), onde as sementes, após pesagem, foram distribuídas homogeneamente; no interior de caixas plásticas para germinação (11,0 x 11,0 $\mathrm{x} 3,5 \mathrm{~cm}$ ) com telas de alumínio em seu interior, sendo adicionados $40 \mathrm{~mL}$ de água. Terminado o preparo, as caixas foram mantidas a $41^{\circ} \mathrm{C}$, por 72 horas (Hampton e TeKrony, 1995). Decorrido esse período, quatro repetições de 50 sementes de cada tratamento foram colocadas para germinar em rolos de papel toalha, da mesma maneira relatada para o teste de germinação. Foram computadas plântulas com todas as partes essenciais bem formadas, no quinto dia após a semeadura. Determinou-se, também, o teor de água das sementes após a condução deste teste, visando a avaliação da uniformidade das condições empregadas, e

e) sanidade - determinada pelo método do papel de filtro, utilizando o congelamento, com incubação em câmara a $20^{\circ} \pm 2^{\circ} \mathrm{C}$, com regime de 12 horas de luz, durante 24 horas e posterior transferência para câmara a $5^{\circ} \mathrm{C} / 24$ horas. Decorrido esse período, as sementes retornaram às condições iniciais de incubação, permanecendo por seis dias (Neergaard, 1979), sendo então avaliada a ocorrência de fungos.

As variáveis foram submetidas à análise de variância e as médias comparadas pelo teste de Duncan, a 5\% de probabilidade, sendo os dados em porcentagem transformados em $\sqrt{x}+0,5$.

\section{RESULTADOS E DISCUSSÃO}

Os resultados da análise de variância revelaram que não houve significância para os efeitos de fatores sobre a germinação e o vigor de semente de milho híbrido superdoce DO-04; com exceção para o teste de frio; os resultados deste teste foram influenciados pela ação conjunta dos lotes e da forma da semente. Quanto à incidência de patógenos, foi verificado efeito significativo na interação dos três fatores estudados, indicando que a aplicação de fungicidas pode responder de modo diferenciado em sementes arredondadas e achatadas, dentro de lotes de milho super-doce.

Analisando individualmente cada fator (Tabela 1), não houve diferenças significativas entre os lotes do híbrido DO-04, quanto ao potencial fisiológico, sendo $77 \%$ o valor médio de germinação, ou seja, 17\% acima do exigido para a comercialização de híbridos de milho super-doce (Brasil, 2005). O vigor também foi considerado satisfatório, pois os valores de germinação das sementes submetidas a baixa temperatura praticamente não diferiram dos observados no teste de germinação. Apenas no teste de envelhecimento acelerado houve discriminação dos lotes, quando o lote 1 foi superior ao lote 2. Nesse teste, os valores do teor de água variaram entre $34,7 \%$ e $35,9 \%$, não excedendo os limites toleráveis indicados por Marcos Filho (1999).

$\mathrm{O}$ efeito do formato da semente (peneiras) diferiu estatisticamente para a maioria das variáveis analisadas. $\mathrm{Na}$ Tabela 1, são observadas diferenças da germinação e do vigor das sementes classificadas em peneiras de crivos oblongos, em relação às retidas em orifícios circulares. Nota-se que as 
TABELA 1. Valores médios de velocidade de germinação (IVG), percentagem de germinação (G) e vigor pelos testes de frio (TF) e envelhecimento acelerado (EA) e resumo da análise de variância; obtidos de análises individualizadas dos fatores Lotes, Peneiras e Fungicidas, em sementes do milho híbrido super-doce, DO-04. Piracicaba, SP, 2004.

\begin{tabular}{|c|c|c|c|c|}
\hline & IVG & $\mathrm{G}(\%)$ & $\mathrm{TF}(\%)$ & $\mathrm{EA}(\%)$ \\
\hline \multicolumn{5}{|l|}{ Lotes } \\
\hline $\mathrm{L} 1$ & $35,7 \mathrm{a}$ & $77,3 \mathrm{a}$ & $77,0 \mathrm{a}$ & $66,1 \mathrm{a}$ \\
\hline L2 & $35,7 \mathrm{a}$ & $76,9 \mathrm{a}$ & $77,2 \mathrm{a}$ & $61,8 b$ \\
\hline L3 & $34,7 \mathrm{a}$ & $77,4 \mathrm{a}$ & $75,4 a$ & $62,9 \mathrm{ab}$ \\
\hline $\mathrm{L}$ & $9,55^{\text {n.s. }}$ & $0,01^{\text {n.s. }}$ & $0,10^{\text {n.s. }}$ & $0,64^{*}$ \\
\hline \multicolumn{5}{|l|}{ Peneiras } \\
\hline$P-15 x^{3} / 4$ & $34,7 b$ & $78,6 a$ & $80,7 \mathrm{a}$ & $62,5 a$ \\
\hline P-20 & $35,9 \mathrm{a}$ & $75,7 b$ & $72,5 b$ & $64,6 \mathrm{a}$ \\
\hline $\mathrm{P}$ & $35,79^{* *}$ & $0,64^{* *}$ & $5,30^{* *}$ & $0,42^{\text {n.s. }}$ \\
\hline \multicolumn{5}{|l|}{ Fungicidas } \\
\hline Testemunha & $34,7 \mathrm{ab}$ & $76,2 \mathrm{a}$ & $70,8 \mathrm{c}$ & $60,0 b$ \\
\hline Fludioxonil & $36,6 a$ & $79,8 \mathrm{a}$ & $82,9 \mathrm{a}$ & $64,1 \mathrm{a}$ \\
\hline $\begin{array}{l}\text { Captan }+ \\
\text { Thiabendazol }\end{array}$ & $33,9 b$ & $75,3 \mathrm{a}$ & $75,2 b$ & $66,0 \mathrm{a}$ \\
\hline Captan + Thiram & $36,2 \mathrm{a}$ & $77,4 \mathrm{a}$ & $77,5 b$ & $64,2 \mathrm{a}$ \\
\hline $\mathrm{F}$ & $38,56^{* *}$ & $0,29^{\text {n.s. }}$ & $1,98^{* *}$ & $0,62^{*}$ \\
\hline
\end{tabular}

Médias seguidas da mesma letra na coluna não diferem entre si a $5 \%$ de probabilidade pelo Teste de Duncan.

${ }^{* *}$ significativo a $1 \%,{ }^{* *}$ significativo a $5 \%$ e ${ }^{\text {ns }}$ não significativo, pelo teste $\mathrm{F}$.

sementes arredondadas de milho super-doce apresentaram desempenho superior nos testes de germinação e de frio, discordando dos resultados de Silva e Marcos Filho (1982) e Ramos (2001) que verificaram que o tamanho e a forma da semente não influenciam a germinação do milho. Talvez a quantidade superior de reservas existente nas sementes arredondadas, com densidade de $1,77 \mathrm{~g} . \mathrm{mL}^{-1}$ e peso de 100 sementes de 17,00 g, que as caracterizam como semente provenientes da posição proximal da espiga, tenha favorecido, mesmo que de maneira pouco acentuada, a porcentagem de germinação (3,7 pontos percentuais) dessa classe de sementes, em comparação às achatadas, com densidade de $1,46 \mathrm{~g} \cdot \mathrm{mL}^{-1}$ e peso de 100 sementes de 14,00 g (provenientes da posição intermediária da espiga). Entretanto, pela variável velocidade de germinação, o resultado foi inverso, quando as sementes achatadas apresentaram índice superior ás arredondadas.
Mondo e Cícero (2005), trabalhando com milho comum, observaram melhor desempenho das sementes achatadas, em comparação às arredondadas, nos testes de frio e envelhecimento acelerado, mesmo sendo estas últimas provenientes da posição proximal da espiga; afirmaram que esse resultado foi determinado pela existência de maior número de torções no eixo embrionário das sementes de formato arredondado. Para milho comum, essas considerações podem constituir uma hipótese a ser confirmada. Entretanto, a semente de milho super-doce não parece seguir o mesmo comportamento, talvez pela ausência de reservas de amido, que ocupam grande parte da semente e podem promover alterações do tipo torções no eixo embrionário.

$\mathrm{O}$ efeito isolado do tratamento fungicida sobre a porcentagem final de germinação de milho super-doce DO-04 não foi significativo, mas alterou todas as demais variáveis estudadas, com grande ênfase no controle de patógenos. Como os resultados de germinação não foram alterados (Tabela 1), pode-se inferir que nenhum produto, mesmo controlando os patógenos presentes nas sementes, foi capaz de beneficiar a germinação inicial dos lotes. Galli et al (2000) obtiveram resultados semelhantes com milho comum, enquanto Von Pinho et al (1995) observaram vantagens no desempenho de plântulas durante a germinação, utilizando vários fungicidas.

Quanto ao vigor (Tabela 1), avaliado pelo teste de envelhecimento acelerado, observa-se que o tratamento com fungicidas beneficiou o desempenho da semente, porém, não sendo verificada diferença significativa entre os produtos utilizados. Por outro lado, o teste de frio (Tabela 2) foi mais sensível para separar os efeitos do tratamento fungicida, sendo o Fludioxonil superior aos demais produtos

TABELA 2. Valores médios do teste de frio (TF) referentes aos efeitos da interação Lotes e Fungicidas sobre o vigor de semente de milho superdoce, híbrido DO-04. Piracicaba, SP, 2004.

\begin{tabular}{lcll}
\hline Fungicidas/Lote & L1 & \multicolumn{1}{c}{ L2 } & \multicolumn{1}{c}{ L3 } \\
\hline Testemunha & $68,0 \mathrm{Bb}$ & $69,7 \mathrm{ABc}$ & $74,8 \mathrm{Aab}$ \\
Fludioxonil & $83,6 \mathrm{Aa}$ & $84,8 \mathrm{Aa}$ & $80,5 \mathrm{Aa}$ \\
Captan + Thiabendazol & $77,1 \mathrm{Aa}$ & $79,1 \mathrm{Aab}$ & $69,4 \mathrm{Bb}$ \\
Captan + Thiram & $79,6 \mathrm{Aa}$ & $75,7 \mathrm{Ab}$ & $77,1 \mathrm{Aab}$ \\
L x F & \multicolumn{3}{c}{$0,38^{* *}$} \\
\hline
\end{tabular}

Médias seguidas da mesma letra minúscula na coluna e maiúscula na linha não diferem entre si pelo Teste de Duncan, 5\% de probabilidade.

${ }^{* *}$ significativo a $1 \%$ pelo teste $\mathrm{F}$. 
no favorecimento do desempenho da semente, sob condições de estresse promovidas nesse teste. Von Pinho et al (1995) encontraram superioridade do produto Metalaxyl na avaliação do teste de frio, mas sem verificar diferenças na emergência de plântulas. Woodstock (1976) relatou que o teste de frio foi inicialmente desenvolvido para avaliar o efeito de tratamentos com fungicidas, para posteriormente tornarse um teste de vigor, uma vez que permite avaliar o efeito combinado do potencial genético da semente, incidência de danos mecânicos, tratamento e condição fisiológica da semente. Portanto, com a superioridade no desempenho fisiológico da semente, utilizando os tratamentos fungicidas, pode-se inferir que sua aplicação, mesmo que não altere a germinação, é recomendada em condições estressantes, semelhantes às promovidas pelos testes de frio e de envelhecimento acelerado.

Com relação à incidência de patógenos, no teste de sanidade foi observada a predominância de $F$. moniliforme e Penicillium sp., enquanto Cephalosporium sp. foi detectado em níveis de até $20 \%$. Aspergillus sp. e demais patógenos ocorreram em incidência inferior a $1 \%$, nas sementes não tratadas. Nesse contexto, para a análise da sanidade, que foi influenciada pela ação conjunta dos três fatores analisados, optou-se pelo desdobramento da interação Peneiras e Fungicidas, dentro de cada lote.

A ocorrência do F. moniliforme (Tabela 3) foi estatisticamente superior para a classe de sementes achatadas (P-20) dentro dos lotes 1 e 2, mesmo após a aplicação dos produtos fungicidas. Entretanto, esse comportamento não foi confirmado no lote 3 , o que dificulta a recomendação de tratamento fungicida associado às peneiras para esse híbrido.
Por outro lado, os diversos fungicidas testados reduziram a incidência desse patógeno, independentemente do formato da semente, onde as combinações Captan + Thiabendazol e Captam + Thiram foram as mais eficientes nesse controle, inclusive com total erradicação. Também Reis et al. (1995) e Goulart e Fialho (1999) observaram eficiência no uso de misturas de fungicidas como Captan + Thiabendazol e Thiram + Thiabendazol para o controle do F. moniliforme. Atualmente, a mistura de fungicidas é utilizada com sucesso por empresas produtoras de semente.

O controle eficaz do $F$. moniliforme é indispensável para milho super-doce, pois a sobrevivência desse patógeno no interior da semente, durante o armazenamento, pode causar podridão e prejudicar o desempenho no campo (Hung et al., 1993). Assim, a baixa eficiência observada com a aplicação do Fludioxonil, no controle de F. moniliforme (Tabela 3), com redução de apenas 31,5 pontos percentuais em relação à testemunha, pode inviabilizar a sua utilização em milho super-doce. Esse produto apresentou tendência de melhor controle na sementes arredondada $(\mathrm{P}-15 \mathrm{x} 3 / 4)$, para os lotes 1 e 2, mas esse comportamento não se confirmou no lote 3 .

Com relação ao Cephalosporium sp. (Tabela 4), mesmo com significância na interação Peneiras e Fungicidas para os lotes 1 e 2, não foi observada variação consistente na sua incidência, em função da forma da semente. Os resultados apenas demonstram que as misturas de fungicidas (Captan + Thiabendazol e Thiram + Thiabendazol) controlaram satisfatoriamente Cephalosporium sp., sendo o Fludioxonil ineficiente, independentemente do lote e da forma da semente. Esse mesmo comportamento de controle do patógeno foi verificado na avaliação do lote 3 , que não apresentou

TABELA 3. Valores médios de incidência de $F$. moniliforme sp., Cephalosporium sp. e Penicillium sp. em diferentes lotes de milho híbrido super-doce DO-04, referentes aos efeitos da interação Peneiras e Fungicidas. Piracicaba, SP, 2004.

\begin{tabular}{|c|c|c|c|c|c|c|}
\hline & \multicolumn{2}{|c|}{ L1 } & \multicolumn{2}{|c|}{ L2 } & \multicolumn{2}{|c|}{ L3 } \\
\hline & $\mathrm{P}-15 \mathrm{x}^{3} / 4$ & $\mathrm{P}-20$ & $\mathrm{P}-15 \mathrm{x}^{3 / 4}$ & $\mathrm{P}-20$ & $\mathrm{P}-15 \mathrm{x}^{3 / 4}$ & P-20 \\
\hline \multicolumn{7}{|l|}{ F. moniliforme sp. } \\
\hline Testemunha & $67 \mathrm{~B}^{1} \mathrm{a}^{2}$ & $78 \mathrm{Ab}$ & $85 \mathrm{Aa}$ & $90 \mathrm{Aa}$ & $90 \mathrm{Aa}$ & $83 \mathrm{Aa}$ \\
\hline Fludioxonil & $55 \mathrm{Bb}$ & $91 \mathrm{Aa}$ & $23 \mathrm{Bb}$ & $77 \mathrm{Aa}$ & $62 \mathrm{Ab}$ & $38 \mathrm{Bb}$ \\
\hline Captan + Thiabendazol & $0 \mathrm{Bc}$ & $4 \mathrm{Ac}$ & $0 \mathrm{Ac}$ & $5 \mathrm{Ab}$ & $0 \mathrm{Ac}$ & $0 \mathrm{Ac}$ \\
\hline Captan + Thiram & $0 \mathrm{Ac}$ & $3 \mathrm{Ac}$ & $1 \mathrm{Ac}$ & $1 \mathrm{Ab}$ & $0 \mathrm{Ac}$ & $0 \mathrm{Ac}$ \\
\hline $\mathrm{FxP}$ & \multicolumn{6}{|c|}{$1,18^{* *}$} \\
\hline
\end{tabular}

${ }^{1}$ Médias seguidas da mesma letra maiúscula na linha, para cada lote, testam o efeito de Peneiras dentro de cada Fungicida e não diferem entre si pelo Teste de Duncan, $5 \%$ de probabilidade.

${ }^{2}$ Médias seguidas da mesma letra minúscula na coluna, para cada lote, testam o efeito de Fungicidas dentro de cada Peneira e não diferem entre si pelo Teste de Duncan, $5 \%$ de probabilidade. 
TABELA 4. Valores médios de incidência de Cephalosporium sp. em diferentes lotes de milho híbrido super-doce DO04, referentes aos efeitos da interação Peneiras e Fungicidas. Piracicaba, SP, 2004.

\begin{tabular}{lrrrr}
\hline \multirow{2}{*}{ Cephalosporium sp. } & \multicolumn{2}{c}{$\mathrm{L} 1$} & $\mathrm{~L} 2$ \\
\cline { 2 - 5 } & $\mathrm{P}-15 \mathrm{x}^{3 / 4}$ & $\mathrm{P}-20$ & $31 \mathrm{x} \mathrm{Aa}^{3 / 4}$ & $\mathrm{P}-20$ \\
\hline Testemunha & $10 \mathrm{~A}^{1} \mathrm{~b}^{2}$ & $5 \mathrm{Bb}$ & $19 \mathrm{Bb}$ & $26 \mathrm{Aa}$ \\
Fludioxonil & $24 \mathrm{Aa}$ & $16 \mathrm{Aa}$ & $0 \mathrm{Bc}$ & $5 \mathrm{Ab}$ \\
Captan + Thiabendazol & $3 \mathrm{Ac}$ & $1 \mathrm{Bb}$ & $0 \mathrm{Ac}$ & $0 \mathrm{Ab}$ \\
Captan + Thiram & $2 \mathrm{Ac}$ & $0 \mathrm{Ab}$ & \multicolumn{2}{c}{}
\end{tabular}

${ }^{1}$ Médias seguidas da mesma letra maiúscula na linha para cada lote testam o efeito de Peneiras dentro de cada Fungicida e não diferem entre si pelo Teste de Duncan, $5 \%$ de probabilidade.

${ }^{2}$ Médias seguidas da mesma letra minúscula na coluna testam o efeito de Fungicidas dentro de cada Peneira e não diferem entre si pelo Teste de Duncan, $5 \%$ de probabilidade.

significância para a interação Peneiras e Fungicidas, onde a incidência de Cephalosporium sp. na testemunha e nas tratadas com Fludioxonil não diferiu estatisticamente, com média de $25 \%$, enquanto as misturas de fungicidas erradicaram esse patógeno.

Na Figura 1, pode ser observada a redução drástica na incidência do Penicillium sp., após o tratamento de semente com as misturas de fungicidas Captan + Thiabendazol e Thiram + Thiabendazol, nos três lotes avaliados. Também o Fludioxonil controlou esse patógeno, mas sem erradicá-lo, lembrando que a sua sobrevivência implica em problemas de queda no potencial fisiológico da semente, durante o armazenamento. A multiplicação do Penicillium sp. é exponencial e passa a consumir as reservas da semente, o que, no caso do milho doce, é ainda mais problemático, em função do alto teor de açúcares (Hung et al, 1993). É importante informar que o efeito da interação Peneiras e Fungicidas só foi verificado no lote 2 (dados não apresentados), demonstrando relação pouco consistente entre a eficiência dos fungicidas e o formato das sementes avaliadas.

Em geral, não foi possível confirmar, com segurança, a possível relação entre a ação dos fungicidas e a forma da

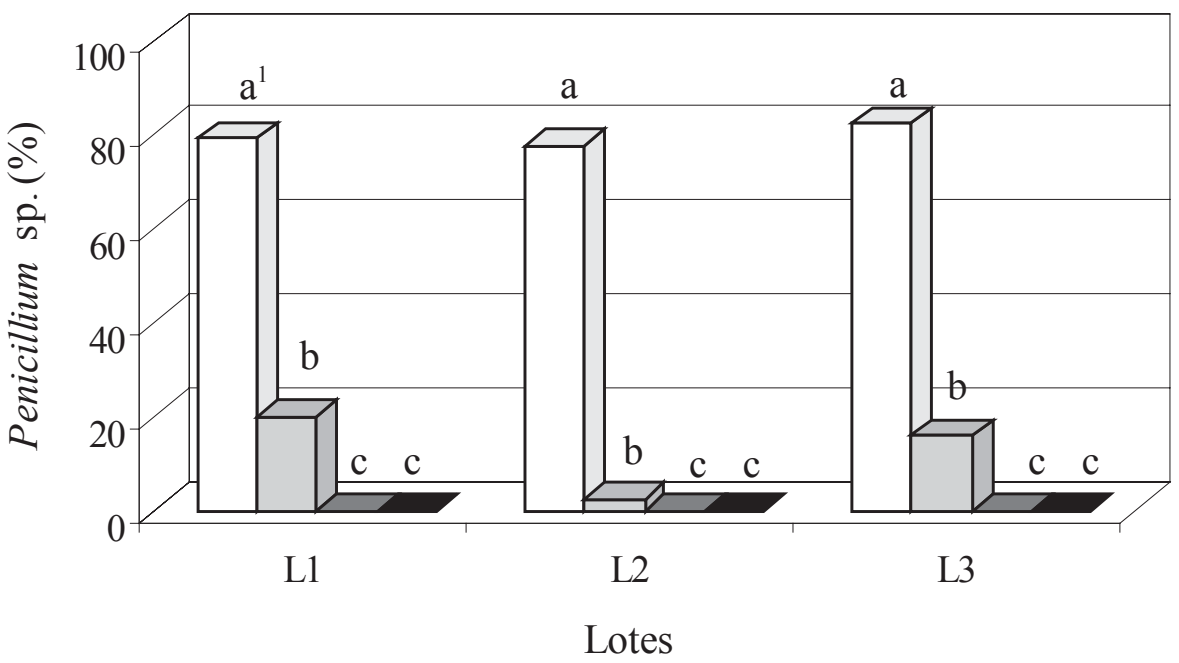

Testemunha $\square$ Fludioxonil $\square$ Captan + Thiabendazol $\quad$ Captan + Thiram

${ }^{1}$ Médias seguidas da mesma letra, dentro de cada Lote, não diferem entre si pelo Teste de Duncan, $5 \%$ de probabilidade.

FIGURA 1. Valores médios da incidência de Penicillium sp. em diferentes lotes de milho híbrido super-doce DO-04, referentes aos efeitos do tratamento fungicida. Piracicaba, SP, 2004. 
semente de milho híbrido super-doce DO-04, considerando a germinação, ovigordesementee aincidência depatógenos.Por outro lado, com relação à eficiência no controle de patógenos associados às sementes, as misturas de produtos fungicidas (Captan + Thiabendazol e Thiram + Thiabendazol) foram altamente eficientes em erradicar os patógenos presentes nas sementes. Quanto ao produto Fludioxonil, mesmo sem controlar satisfatoriamente a incidência de patógenos, houve interferência positiva no vigor das sementes, identificada principalmente no teste de frio, merecendo novos estudos que avaliem doses de aplicação.

\section{CONCLUSÕES}

As sementes arredondadas de milho híbrido super-doce DO-04 localizadas na base da espiga apresentam desempenho superior ao das achatadas.

Os tratamentos fungicidas não interferem na porcentagem de germinação e favorecem o vigor da semente de milho híbrido super-doce DO-04. As combinações de produtos, Captan + Thiabendazol e Captan + Thiram são eficientes no controle de F. moniliforme, Cephalosporium sp. e Penicillium sp., associados à semente de milho super-doce.

\section{AGRADECIMENTOS}

À Dr. Maria Heloísa Duarte Moraes, pelo auxílio na condução dos testes de sanidade, junto aos Departamentos de Entomologia, Fitopatologia e Zoologia Agrícola da ESALQ - USP, Piracicaba, SP e à empresa produtora de sementes Dow AgroSciences ${ }^{\circledR}$, na pessoa do pesquisador Roberto Wenceslau de Carvalho, pela doação das sementes utilizadas neste experimento.

\section{REFERÊNCIAS}

BRASIL. Ministério da Agricultura e Reforma Agrária. Regras para análise de sementes. Brasília: SNDA/ DNDV/32 CLAV, 1992. 365p.

BRASIL. Produção e Comércio de Sementes, 2005. ANEXO VII. (Instrução normativa, nº25 de 16/12/2005). MINISTÉRIO DA AGRICULTURA, PECUÁRIA E ABASTECIMENTO. Disponível em: $<$ http://www.abrasem. com.br/legislacao_sac/01_producao_e_comercio/031_1612-2005_estabelecidos_os_padroes_nacionais_de_sem ent. htm>. Acesso em: 21 de set. 2006.

CASEIRO, R.F.; MARCOS FILHO, J. Procedimentos para condução do teste de frio em sementes de milho: pré resfriamento e distribuição do substrato no interior da câmara fria. Revista Brasileira de Sementes, v.24, n.2, p.611. 2002.

CARVALHO, N.M.; NAKAGAWA, J. Sementes: ciência, tecnologia e produção. 4.ed. Jaboticabal: FUNEP, 2000. $588 \mathrm{p}$.

DOUGLAS, S.K.; JUVIK, J.A.; SPLITTSTOESSER, W.E. Sweet corn seedling emergence and variation in kernel carbohydrate reserves. Seed Science and Technology, Zürich, v.21, n.3, p.433-445, 1993.

GALLI，J.A.; FESSEL， S.A.; SADER， R.; PANIZZI, R.C.; COSTA, P.R.R. Influência do tratamento químico na população de fungos, na germinação e no vigor de sementes de milho. Revista Brasileira de Sementes, Brasília, v.22, n.2, p.245-249, 2000.

GOULART, A.C.P.; FIALHO, W.F.B. Incidência e controle de Fusarium moniliforme Sheldon em sementes de milho. Revista Brasileira de Sementes, Brasília, v.21, n.1, p.216221, 1999 .

HAMPTON, J.G.; TEKRONY, D.N. Accelerated ageing test. In: Handbook of vigour tests methods. Zürich: International Seed Testing Association, p.35-50,1995.

HUNG, P.E.; FRITZ, V.A..; KOMMEDAHL, T.; MARKHART III, A.H.; WATERS Jr., L. Treating shrunken-2 sweet corn with fungicide infused via acetone, HortScience, Alexandria, v.28, n.4, p.340-342, 1993.

KNIEP, K.R. MASON, S.C. Kernel breakage and density of normal and opaque-2 maize grains as influenced by irrigation and nitrogen. Crp Science, Madison, v.29, n.1, p.159-163, 1989.

LUZ, W.C. da. Tratamento de sementes de milho com fungicidas. Passo Fundo: Embrapa-CNPT, Circular Técnica, 7. 1997.

McDONALD, M.B.; SUlliVAN, J.; LAWER, M.J. The pathway of water uptake in maize seeds. Seed Science and Technology, Zürich, v.22, n.1, p.79-90, 1994.

MACHADO, J.C. Patologia de sementes: significado e atribuições. In: CARVALHO, N.M.; NAKAGAWA, J. Sementes: ciência, tecnologia e produção. 4.ed. Jaboticabal: FUNEP, 2000. 588p.

MAGUIRE, J.D. Speed of germination aid in selection and evaluation for seedling and vigor. Crop Science, Madison, v.2, n.2, p.176-177, 1962.

MARCOS FILHO, J. Teste de envelhecimento acelerado. In: KRZYZANOWSKI, F.C.; VIEIRA, R.D.; FRANÇA NETO, J.B. (Ed). Vigor de sementes: conceitos e testes. Londrina: ABRATES, p.3-1 - 3-21, 1999. 
MONDO, V.H.V.; CICERO, S.M. Análise de imagens na avaliação da qualidade de sementes de milho localizadas em diferentes posições na espiga. Revista Brasileira de Sementes, Pelotas, v.27, n.1, p.9-18, 2005.

NASCIMENTO, W.M.; PESSOA, H.B.S.; BOITEUX, L. Qualidade fisiológica de sementes de milho doce submetidas a diferentes processos de colheita, debulha e beneficiamento. Pesquisa Agropecuária Brasileira, Brasília, v.29, n.8, p.1211-1214, 1994.

NEERGAARD, P. Seed Pathology. London: McMillan, v.1, 1979. 839p.

PETERSON, J.M.; PERDOMO, J.A.; BURRIS, J.S. Influence of kernell position mechanical damage and controlled deterioration on estimats of hybrid maize seed quality. Seed Science and Technology, Zürich, v.23, p.647-657, 1995.

RAMOS, N.P. Efeito do tamanho de semente de milho doce e comum (Zea mays L.) sobre seu desempenho vegetativo e produtivo, sob condições de estresse por profundidade de semeadura. 2001. 81f. Dissertação (Mestrado em Produção e Tecnologia de Sementes) - Faculdade de Ciências Agrárias e Veterinárias, Universidade Estadual Paulista, Jaboticabal, 2001.

REIS, A.C.; REIS, E.M.; CASA, R.T.; FORCELINI, C.A. Erradicação de fungos patogênicos associados a sementes de milho e proteção contra Pythium sp. presente no solo pelo tratamento com fungicidas. Fitopatologia Brasileira, Brasília, v.20, n.4, p.585-590, 1995.

SHIEH, W.J.; McDONALD, M.B. The influence of seed size, shape and treatment on inbred seed corn quality. Seed Science and Technology, Zürich, v.10, n.2, p.307-313, 1982.

SILVA, W.R.; MARCOS FILHO, J. Influência do peso e do tamanho das sementes de milho sobre o desempenho no campo. Pesquisa Agropecuária Brasileira, Brasília, v.17, n.12, p.1743-1750, 1982.

STYER, R.C.; CANTLIFFE, D.J. Dependence of seed vigor during germination on carbohydrate source in endosperm mutants of maize. Plant Physiology, v.76, p.169-200, 1983.

VON PINHO, E.V.R.; CAVARIANI, C.; ALEXANDRE, A.D.; MENTEN, J.O.M.; MORAES, M.H.D. Efeito do tratamento fungicida sobre a qualidade sanitária e fisiológica de sementes de milho (Zea mays L.) Revista Brasileira de Sementes, Brasília, v.17, n.1, p.23-28, 1995.

WATERS-JR, L.; BLANCHETTE, B. Prediction of sweet corn field emergence by conductivity and cold tests. Journal of American Society Horticultural Science, Alexandria, v.108, n.5, p.778-781, 1983.

WOODSTOCK, L.W. Progress reports on seed vigor testing handbook. Newsletter of Association of Official Seed Testing Analysts. 50, n.2, p.1-78, 1976. 